\title{
Mediumtermynvooruitskatting deur die ontleding en sintese van periodisiteit
}

\author{
R. Reinecke \\ Departement Bedryfsingenieurswese, Universiteit van Stellenbosch
}

\begin{abstract}
The programme suit TEMPOS is an aid to medium-term forecasting of national major economic time series. It is based on the assumption that the well-known recurrent, but non-periodic business cycles can be represented by simple but strictly periodic cyclic movements, each driven by a separate but not necessarily known external economic factor. As the elements of such a model are individually extrapolatable, the model as a whole may be extrapolated over a limited horizon.

S. Afr. J. Bus. Mgmt. 1981, 12: $22-25$
\end{abstract}

Die suite rekenaarprogramme TEMPOS is 'n hulpmiddel vir vooruitskatting in die mediumtermyn van nasionale omvang ekonomiese tydreekse. As uitgangspunt geld die aanname dat die bekende herhalende maar nie-periodieke konjunktuurgolwe voorgestel kan word deur eenvoudiger maar streng periodieke golwe, elk gedrewe deur eiesoortige eksterne ekonomiese faktore.

S.-Afr. Tydskr. Bedryfsl. 1981, 12: $22-25$
Bekende modelle vir mediumtermynvooruitskatting Met mediumtermyn word 'n tydperk van drie maande tot drie jaar bedoel. Tegnieke wat reeds redelik suksesvol vir sodanige vooruitskatting aangewend word, is die volgende: (Adam, ${ }^{1, p .336}$ )

Delphi-tegniek: 'n Paneel deskundiges word ondervra met behulp van opeenvolgende vraelyste.

Box-Jenkins: Hierdie tegniek behels die passing van 'n wiskundige model uit 'n familie van modelle. Die passing van die model word met onder meer die korrelogram ondersoek. Die metodiek is hoog aangeskryf maar dit is ook tydrowend en duur om die model en parameters suksesvol te bepaal.

Regressiemodelle: Funksioneel vind hierdie metode verwantskappe tussen die gegewe tydreeks en ander ekonomies mededingende tydseries of tussen interne veranderlikes. 'n Lineêre vergelyking in terme van verskeie veranderlikes word opgestel.

Ekonometriese modelle: Hierdie metode behels 'n stelsel van interafhanklike regressievergelykings, die parameters waarvan gelyktydig beraam word.

X-11 Metode: Hierdie metode ontleed 'n tydreeks in terme van 'n seisoenale patroon, die neiging/sikliese patroon en willekeurige elemente. Die metode is algemeen in gebruik en lewer goeie resultate.

Ander tegnieke in algemene gebruik is verder ook marknavorsing, die metode van historiese analogie en koopplanopnames.

\section{Dle X.11 metode}

Die TEMPOS metode is geskoei op die $\mathrm{X}-11$ benadering en daardie metode word dus verder bespreek.

Die X-11 tegniek onderskei tussen 'n tendens, 'n konjunktuurgolf, seisoenaliteit en geruis. Hierdie komponente van ' $n$ tydreeks word ontleed en word dan weer saamgevoeg om 'n model van die tydreeks te vorm.

McLaughlin ${ }^{2, p .203}$ wat die handleiding vir die X-11 programmatuur opgestel het, merk soos volg op: 'Business cycles tend to the recurrent but not periodic'. Hierdie verskynsel kan maklik in verskeie tydreeks waargeneem word. So word die klassieke driejaargolf dikwels gevind 
deur pieke te tel en dit in die totale aantal jare van geskiedenis in te deel. Sodra 'n poging egter aangewend word om die gemiddelde golfvorm vas te stel verdwyn die vroeër redelike opsigtelike golf byna in geheel. Die rede daarvoor is inderdaad dat die golf wel herhalend is maar swak periodiek is.

As gevolg van hierdie verskynsel meld McLaughlin', p.209 dan ook op: "It is very important to understand that in all the method II variants (dit is nou variante van die $X-11$ metode) only the seasonal pattern is forecast'.

Die X-11 het dus 'n ingeboude beperking en die ontwikkeling van TEMPOS was juis 'n poging om minstens 'n deel van dáárdie beperking op te hef.

\section{Beginsels van 'TEMPOS'}

'n Paar jaar gelede het die skrywer opdrag van die Buro vir Ekonomiese Ondersoek ontvang om 'n benadering en programmatuur daar te stel vir die ontleding van 'n konjunktuurgolf. 'n Eerste poging was teleurstellend juis as gevolg van die sterk nie-periodieke eienskap van sekere toetsreekse en ekonomiese data wat gebruik was. Ondersoek is gedoen of die komplekse beweging van ekonomiese data nie moontlik die gesámentlike effek kon verteenwoordig van verskeie sikliese verskynsels in die ekonomie nie.

Hierdie ondersoek was gegrond op die waarneming dat ekonomiese tydreekse nooit van menslike instellings en menslike optrede losgemaak kan word nie. Die mens en sy instellings toon traagheid van reaksie op 'n uitwendige stimulus. Indien 'n gegewe stimulus egter wel 'n reaksie veroorsaak staan al die normale effekte in teenstelling met die nuwe stimulus en neig dus om die reaksie te neutraliseer en die gemete grootheid na normaal te laat terugkeer.

Hierdie traagheid van reaksie wat lei tot vertraging maar ook later oorreaksie nadat die stimulus verdwyn het, is baie analoog aan 'n eenvoudige meganiese stelsel bestaande uit 'n massa aan ' $n$ veer. In hierdie geval veroorsaak 'n stimulus (impuls) 'n voortgesette sikliese beweging met tyd; die sogenaamde Eenvoudige Harmoniese Beweging.

As hierdie eenvoudige meganisme egter kompleks gemaak word deur koppeling met ander soortgelyke stelsels met verskillende natuurlike frekwensies, asook deur die bybring van dempende effekte of terugvoering, verdwyn die eenvoud van reaksie. Dan is die beweging moontlik nog herhalend maar nie meer periodiek nie - minstens nie oor 'n kort waarnemingsperiode nie.

Dit het redelik gelyk om te aanvaar dat 'n tydreeks van minstens nasionale omvang, bv. 'Waarde van bouplanne goedgekeur' of 'Verkope van staal' deels afhanklik is van die nasionale en internasionale ekonomie. Daarby is dit bekend dat die ekonomie en onderdele daarvan dinamies optree soos Forrester ${ }^{5}$ herhaaldelik aangetoon het.

Die tegniek TEMPOS (Tydreeks Evaluasie en Modellering deur PeriodisiteitsOntleding en -Sintese) wat deur die skrywer ontwikkel is, is daarom gefundeer op die aanname dat die totale beweging van ekonomiese tydreekse bestaan uit:

- mediumtermyn gladde tendense, geskei deur

- breekpunte in die geskiedenis waar daardie tendense verander het
- 'n aantal onafhanklike golfbewegings elk eie aan 'n faset van die ekonomie of aan 'n menslike instelling

- willekeurige geruis van onverklaarbare oorsprong.

\section{Tegnieke van TEMPOS Ontleding}

Die TEMPOS ontleding begin deur die identifikasie van breekpunte aan die hand van 'n grafiese voorstelling van die data en agtergrondskennis van die betrokke tydreeks. Hierdie breekpunte kom voor waar ingrypende langtermynveranderings in ekonomiese toestande intree. Die gevolg is ' $n$ verandering in helling of 'n stapinkrement of -dekrement wat sigbaar is vir die ontleder.

Standaard regressieroetines word nou gebruik om die bes passende tendenslyn deur elke segment van data tussen breekpunte te vind. Die korrelasiekoëffisiënt en die standaard skattingsfout dien as maatstaf vir die keuse van die mees geskikte regressiemodel.

Figuur 1 toon die samegestelde groeilyn van passasiersmotorverkope van 1962 tot 1979 teen die agtergrond van die oorspronklike data.

Daarna word die oorspronklike data genormaliseer na 'n langtermyn helling van nul deur die deling daarvan deur die samegestelde groeilyn in Fig. 1 getoon. Die resultaat word in Fig. 2 getoon.

Die resultaat van hierdie transformasie is data wél sonder helling op die mediumtermyn, maar met nog die samegestelde golwing te wyte aan die konjunktuur asook willekeurige geruis teenwoordig. Daarna moet hierdie data ondersoek word vir beduidende golfelemente. Vir daardie doel is daar roetines in the suite ingesluit wat die kragspektrum van die data verskaf asook roetines vir die ontwikkeling van die korrelogram van die getransformeerde data.

Die kragspektrum van die data is sensitief vir amplitude van herhalende beweging van die data terwyl die korrelogram meer sensitief is vir net periodisiteit, afgesien van amplitude. As sodanig is die korrelogram veel kragtiger as die kragspektrum wat in die praktyk net vir 'n eerste ontleding dien. Die soektog na 'n stel beduidende golwe is dikwels moeilik en daarvoor word op die korrellogram staatgemaak.

Die tentatiewe golflengte, sê 36 maande, word ondersoek deur die gemiddelde golfvorm van lengte 36 maande te vind en om daardie besondere golf, element vir element, in die data in te deel. Sodoende word daardie besondere periodisiteit uit die genormaliseerde data gestroop. (Met die bepaling van die gemiddelde golfvorm word uitskieterpunte in 'n element van die golfvorm geidentifiseer deur die maatstaf $|\mu-x|>2 \sigma$ en verder buite rekening gelaat.)

Die sodanige gestroopte data word dan ondersoek vir 'n verdere dominante golfvorm aan die hand van 'n nuwe korrelogram. Soos in die geval van die Box-Jenkins metodiek (Wheelwright ${ }^{3}$ p.149), is hierdie hulpmiddel baie suksesvol om versteekte periodisiteit uit te wys.

Die proses word vir daaropvolgende kandidaat beduidende periodisiteite herhaal. Indien die stel bydraende periodisiteite suksevol geïdentifiseer en almal stelselmatig uit die data gestroop is behoort die korrelogram te verval na 'n beeld van willekeurige geruis. 


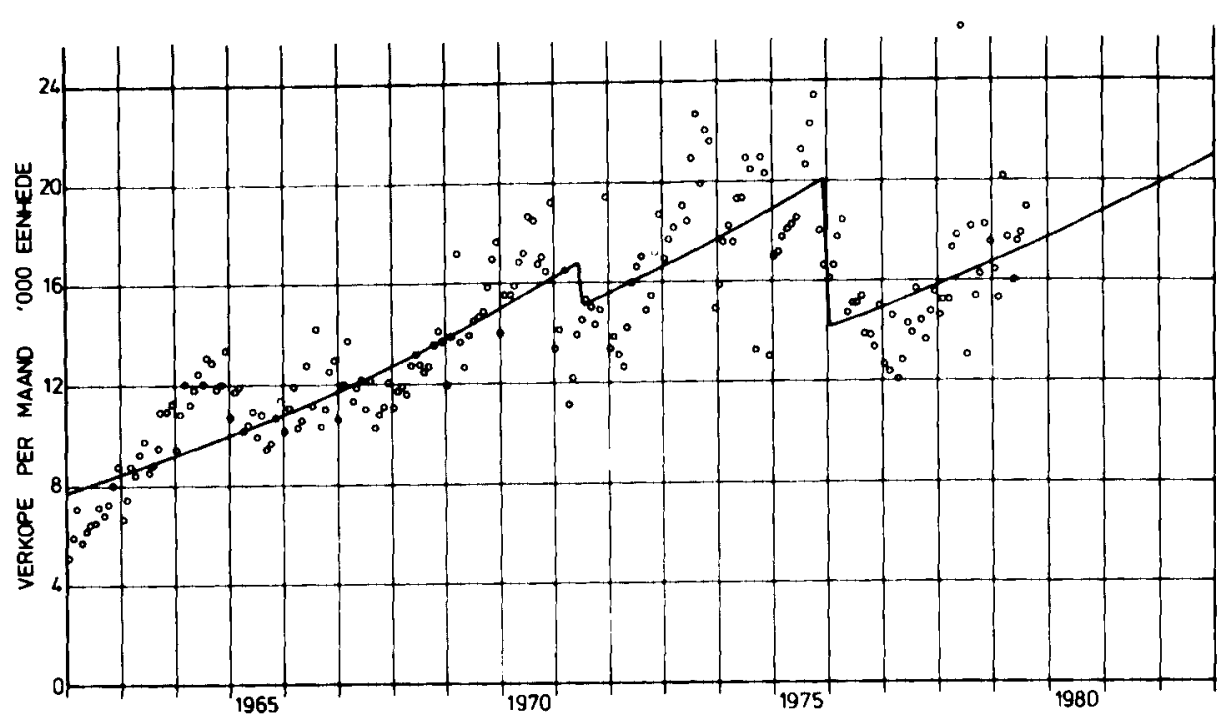

Tig. 1 Passasiersmotors: Samegestelde groeilyn teen die agtergrond van die oorspronklike data

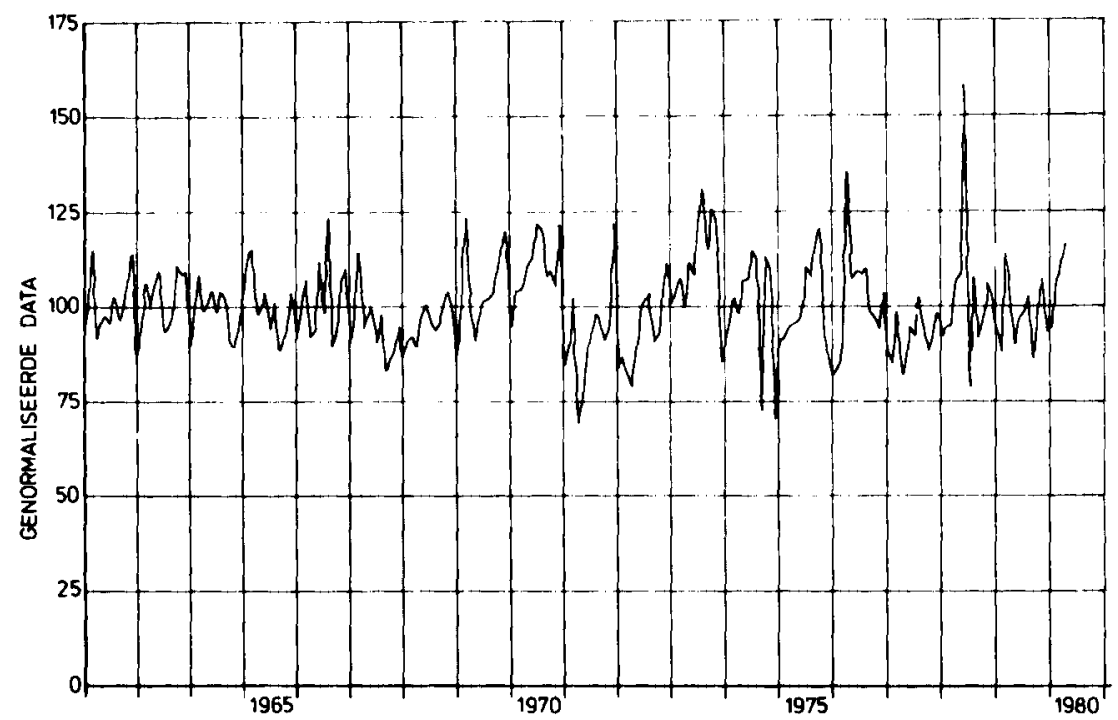

Fig. 2 Passasiersmotors: Beweging van data om samegestelde groeilyn

\section{Sintese}

Die TEMPOS model word daarna gesintiseer deur die verskeie elemente multiplikatief saam te voeg. Teekens ${ }^{4, ~ p .15}$, beskryf hierdie proses en die samegestelde groeilyn getoon in Fig. 1 vorm die kern van die uiteindelike model.

Daarna word die eerste beduidende golf wat gevind is óm hierdie kern ontwikkel en Fig. 3 toon die posisie van die ontplooiing van die uiteindelike model na daardie stap. In hierdie geval is die 12-maandelikse golf, oftewel die seisoenale patroon, as eerste beduidende periodisiteit, bygevoeg.

Die model word dan verder verryk deur die tweede beduidende golfvorm, sê dié van die 36-maandgolf (die klassieke konjunktuurgolf), ook multiplikatief om die vorige model te wikkel.

Wanneer die golfvorms almal saamgestel is in die model bly net die oorblywende willekeurige geruis oor om in aanmerking geneem te word. Dit word gedoen deur die lynmodel te verander na 'n ooreenstemmende bandmodel begrens deur (gewoonlik) twee standaard afwykings van die oorblywende geruis.

Aangesien die volledige model saamgestel is uit afsonderlik ekstrapoleerbare elemente is die model as geheel ook ekstrapoleerbaar. Figuur 4 toon die model as band geekstrapoleer met drie jaar. Die oorspronklike data word weer eens in die agtergrond getoon.

Hierdie tipe model is in der waarheid hoofsaaklik 'n model vir interpolasie. Ekstrapolasie is egter moontlik en geregverdig tot die mate waar die aannames ten opsigte van saamgestelde ekonomiese invloede en die Forrester tipe ekonomiese dinamika korrek is. Die ontledingsfase van TEMPOS is egter nie outomaties nie en oordeelsfoute kan begaan word wat segmentasie en keuse van kandidaat periodisiteite betref. Dan bly die onvoorsiene en dramatiese nuwe invloede op die mark, ook natuurlik oor om die akkuraatheid van vooruitskattings te verlaag.

Die ondervinding het geleer dat TEMPOS redelike resultate lewer vir die ontleding van primêre tydreekse, soos byvoorbeeld 'Voertuigverkope' en 'Bouplanne 


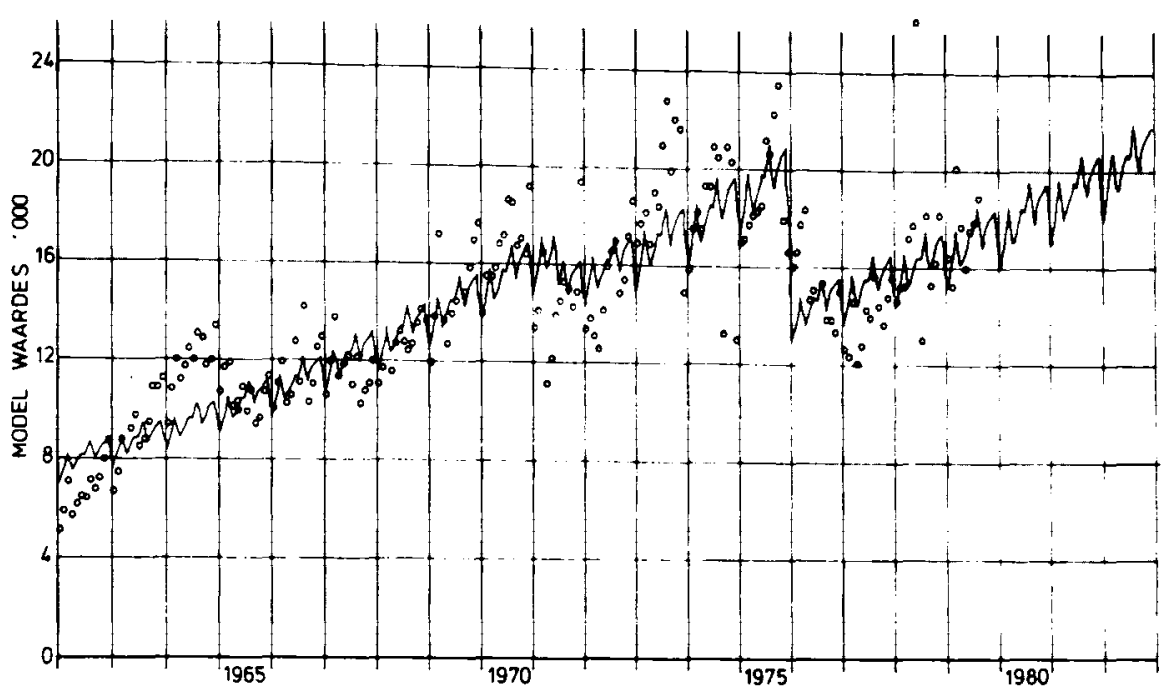

Fig. 3 Passasiersmotors: Samegestelde groeilyn plus seisoenale patroon

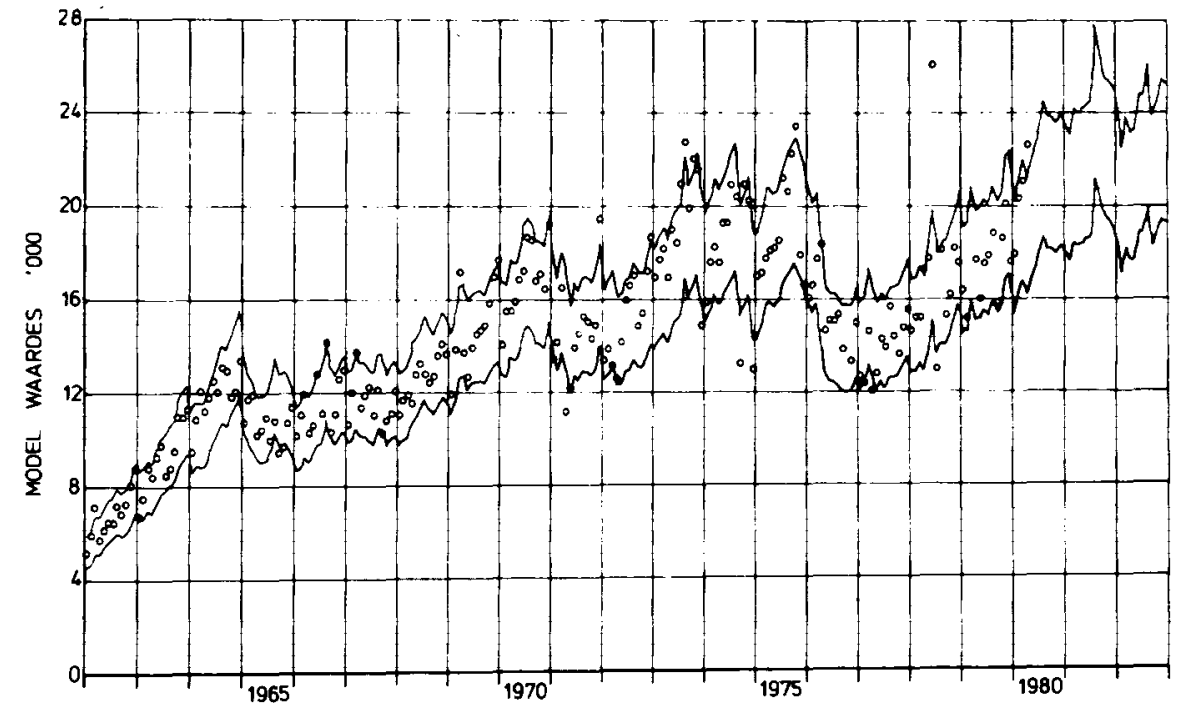

Fig. 4 Passasiersmotors: Finale ekstrapoleerbare model in bandvorm

goedgekeur'. Veral draaipunte in die ekonomie word gereeld verbasend goed vooruit getoon deur die ontleding van Passasiersmotorverkope. Daardie tydsreeks word as deurlopende eksperimentele tydreeks gereeld ses-maandeliks op datum gebring by Stellenbosch.

\section{Summary}

The programme suit TEMPOS is an aid to medium term forecasting of the behaviour of major economic time series. It shares features of the methodology of the X-11 and the Box-Jenkins system.

This forecasting system is based on the assumption that the well-known recurrent, but non-periodic business cycles can be represented by a combination of simple but strictly periodic cyclic movements, each driven by separate but not necessarily known economic factors.

The step by step decomposition of a time series involves the identification of discontinuities of the basic characteristics of the time series, the determination of trend by means of the appropriate regression analysis model and involves the search for significant cyclic movement of the data using the normalized correlogram as exploratory tool.

The components thus identified are then recombined by a multiplicative process into a model of the original time series. As the elements of such a model are individually extrapolatable, the model as a whole may be extrapolated over a limited horizon.

Good results have been found on major time series such as passenger vehicle sales.

\section{Verwysings}

1 ADAM, E.E. \& EBERT, R.J. Production and Operations Management, Prentice Hall, Englewood Cliffs, 1978.

2 McLAUGHLIN, R.L. Time Series Analysis, 1974.

3 WHEELWRIGHT, S.C. \& MAKRIDAKIS, S. Forecasting Methods for Management, 2e Uitgawe, Wiley, 1977.

4 TEEKENS, R. Prediction Methods in Multiplicative Models, Rotterdam, University Press, 1972.

5 FORRESTER, J.W. Principles of Systems, Wright-Allen Press, Inc., 1972. 